\title{
İşyeri Şiddeti Çalışmalarının Bibliyometrik Analizi
}

\author{
DOI: $10.26466 /$ opus.885707
}

\section{Fatih Seyran *}

* PhD, T.C. Sağlık Bakanlığı, Yönetim Hizmetleri Genel Müdürlüğü, Çankaya/Ankara

Öz

ORCID: $\underline{0000-0001-8546-1145}$

Üretim ve hizmet sektöründe giderek artan işyeri şiddeti, çalışma yaşamı için dikkat çekici olumsuzluklara yol açmaktadır. Daha çok yoğun ve riskli koşullar altında çalışanların maruz kaldığı işyeri şiddetinin çeşitli boyutları ise özellikle son dönem çalışmalarında kapsamlı şekilde yer almaktadır. Çalışmanın amacı "işyeri şiddeti" ile ilgili alanyazında mevcut olan ana temaları belirlemek ve çalışma hayatında bu kavrama yönelik gelecek araştırma yönelimlerine katkı sağlayacak bir zemin hazırlamaktır. Bu amaç doğrultusunda Web of Science (WoS) Core Collection veri tabanında yer alan 1393 adet makale, araştırma kapsamına dahil edilmiştir. Bibliyometrik analiz yöntemi ile yapılan çalışma için $R$ ve VOSviewer yazılımları kullanılmıştır. Çalışma kapsamında "işyeri şiddeti" konulu makalelerin yer almaya başladığı 1994 yılından 2020 yılı sonuna kadar WoS tabanında taranan 27 yıllık Ingilizce dilindeki verilerin kıyaslamalı bulgularına yer verilmiştir. Yapılan analizde en çok atıf alan ilk 5 makale 1996-2005 yılları arasında olmuştur. İşyerinde şiddet konusunu en çok ele alan dergi türlerinin \%75'inin să̆llk alanıyla ilgili olduğu görülmektedir. "İşyeri şiddeti" konusunda en çok araştırma yapan ülkeler; $A B D$, Çin, Avustralya, Kanada, İtalya ve Türkiye olmuştur. Ülkelerin yazdıkları makalelerin atıf gücü ve atıf ağlar incelendiğinde ABD'nin 9338 atıf ve 3573 bağlantı gücü ile ilk sırada yer aldığı görülmektedir. Yapılan çalışma sonucunda işyeri şiddeti konusunda üretilen bilimsel yayınların çeşitlilik ve etkileşim açısında giderek artış gösterdiği ortaya çıkmıştır.

Anahtar Kelimeler: İşyeri Şiddeti, Bibliyometrik Analiz, Çalışma Hayatı 
ISSN:2528-9527

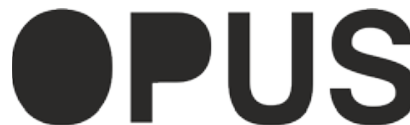

Uluslararası Toplum Araştırmaları Dergisi International Journal of Society Researches
E-ISSN : 2528-9535

Yıl Year: 11

Cilt Volume: 17

Sayı Issue:36

Nisan April 2021

Makalenin Gelis Tarihi Received Date. 23/02/2021

Makalenin Kabul Tarihi Accepted Date. 22/04/2021

\title{
Bibliometric Analysis of Workplace Violence Studies
}

\begin{abstract}
The increasing workplace violence in the production and service sector causes remarkable negativities for the working life. Various dimensions of workplace violence that employees are exposed to, mostly under intense and risky conditions, take place especially in recent studies. The aim of the present study is to determine the main themes existing in the literature on "workplace violence" and to lay a foundation that will contribute to future research orientations towards this concept in business life. For this purpose, 1393 articles in the Web of Science (WoS) Core Collection database were included in the scope of the research. $R$ and VOSviewer software were used for the study performed with bibliometric analysis method. Within the scope of the study, comparative findings of 27 years of English data scanned on the WoS base from 1994, when articles on "workplace violence" began to take place, were included. The first 5 articles with the most citations in the analysis are between 1996-2005. It is seen that $75 \%$ of the journal types dealing with workplace violence are related to the field of health. Countries with the most studies on "workplace violence"; USA, China, Australia, Canada, Italy and Tur$k e y$. When the citation power and citation networks of the articles written by the countries are examined, it is seen that the USA takes the first place with 9338 citations and 3573 connection power. As a result of the study, it has been revealed that scientific publications on workplace violence have increased in terms of diversity and interaction.
\end{abstract}

Keywords: Workplace Violence, Bibliometric Analysis, Work Life 


\section{Giriş}

Uluslararası Çalışma Örgütü (ILO), çalışma hayatındaki "şiddet ve taciz" terimlerinin kapsamın fiziksel, psikolojik, cinsel veya ekonomik zararı amaçlayan, bunlarla sonuçlanan veya sonuçlanma ihtimali olan, bir defaya mahsus veya tekrarlanan, kabul edilemez bir dizi davranış, uygulama veya bunlarla ilgili tehditler olarak değerlendirmektedir (ILO, 2019, s.4). İşü̈cü sağlayan bir çalışanın herhangi bir kişi tarafından tehdit edici ifade veya saldırgan bir davranışa maruz kalarak risk altında olduğuna inanması halinde işyeri şiddetine uğradığı kabul edilir (Chappell ve Di Martino, 2006, s.10).

İşyeri şiddeti günümüzde dikkat çekici boyutlara ulaşan sonuçlarıyla ayrı bir çalışma alanı haline gelmiştir. Bugün dünyanın farklı bölgelerinde asayiş, konaklama, ulaşım, eğitim ve sağlık gibi birçok sektörde farklı hizmetler sunan milyonlarca işgören zaman zaman şiddete uğramaktadır. Dünyada birçok çalışan, işleriyle ilgili durumlarda istismar edilmekte, tehdit edilmekte, saldırıya uğramakta veya başka saldırı davranışlarına maruz kalmaktadır (Di Martino ve Musri, 2001, s.7). İşçi sağlığı ve iş güvenliği konusunda risk etmenleri içeren çoğu işyerinde stres, iş kazaları ve yaralanmaların yanı sıra şiddet ve taciz olayları da görülebilmeketedir (Gözlü, 2020). Bu nedenle tüm ülkelerde çeşitli sektörlerdeki çalışma ortamlarında çalışanlara karşı faklı türde ve sıklıkta şiddet olayları yaşanabilmektedir. İşgörenler işyerlerinde veya işleriyle ilgili olarak farklı ortamlarda cinayete kurban girmekte, tecavüze uğramakta, soygun, hırsızlık, gasp gibi nedenlerle rehin alınarak eziyete maruz kalabilmektedir (Çakır, 2010; Rugala ve Isaacs, 2003; Tian ve ark., 2020). İşyerlerinde çalışanlara genel olarak yumruk atmak, tekme atmak, tokat atmak, tartaklamak, tükürmek, zorbalık, şantaj, ayrımcllık, tehdit etmek, gözdağı vermek, kaba davranmak, küfür etmek, bağırmak, aşağılamak, argo konuşmak, cinsel tacizde bulunmak gibi çeşitli şekillerde saldırgan davranışlar uygulanmaktadır (Chappell ve Di Martino, 2006; Duhart, 2001; Rugala ve Isaacs, 2003; Yıldız ve ark., 2011).

Ulusal Suç Mağduriyet Araştırmasina (NCVS) göre, ABD'de 1993 ve 1999 yılları arasında, 12 yaşında veya daha büyük olanlardan işyerinde veya görevde olan kişilere karşı yılda ortalama 1.7 milyon şiddet olayı gerçekleştirilmiştir. NCVS tarafından ölçülen ölümcül olmayan şiddete ek olarak, yılda yaklaşık 900 işle ilgili cinayet ortaya çıkmıştır. İşyerinde şiddet, bahse- 
dilen 7 yıllık dönemde tüm şiddet suçlarının \%18'ini oluşturmuştur (Duhart, 2001, s.1). 2005 yılında yapılan başka bir araştırmaya göre Avrupa ülkelerinde işyerinde fiziksel şiddete maruz kalan işçiler, Hollanda' da \%10, Fransa ve Birleşik Krallık'ta \%9 ve İrlanda'da \%8 olarak rapor edilmiştir. Bildirilen işyerinde cinsel taciz ise Avrupa'da ve Çek Cumhuriyeti'nde \%10, Norveç'te \%7, Türkiye ve Hırvatistan'da \% 6, Danimarka, İsveç, Litvanya ve İngiltere'de ise \%5'tir (Parent-Thirion ve ark., 2007, s.36).

Dünyanın farklı ülkelerinde yapılan araştırmalarda çalışanların en fazla maruz kaldığı şiddet türünün sözle gerçekleştirildiği, ardından fiziksel şiddetin ve cinsel şiddetin yaşandığı görülmektedir (Aydemir ve ark., 2020; Choi ve Lee, 2017; Duan ve ark., 2019; Hidıroğlu ve ark., 2019; Kale ve ark., 2020; Lanctot ve Guay, 2014; Li ve ark., 2019; Savaş ve ark., 2020; Shaikh ve ark., 2020; Singh ve ark., 2019; Speroni ve ark., 2014; Tian ve ark., 2020).

İşyeri şiddet olaylarının ardından bireylerde travma sonrası stres bozuklukları, depresyon, anksiyete bozuklukları, çok yönlü kişilik bozuklukları, duygu durum bozuklukları, intihar eğilimleri, alkol ve uyuşturucu bağımllıkları, düşük benlik saygısı, sosyal yabancılaşma ve daha az psikolojik işlevler ortaya çımaktadır. Buna ek olarak işten ayrılma niyeti, devamsızlık, iş tatminsizliği, iş performansı düşüklügü ve örgütsel bağl1lı̆̆ın azalması gibi sonuçlar ise örgütler üzerinde olumsuz etkilere neden olmaktadır (Antão ve ark., 2020; Arın, 1996; Duan ve ark., 2019; Hamlin ve Hoffman, 2002; Liu ve ark., 2018; Öztürk ve ark., 2018; Stadnyk, 2004).

İşyerinde şiddet, günümüzde artık uluslararası ölçekte ele alınan ve çözüm üretilmeye çalışlan bir sorun olarak görülmektedir. 185 üye ülkeye sahip olan ILO tarafından 2019 yılında iş dünyasında şiddet ve tacizin önlenmesi amacıyla uluslararası standartların oluşturulduğu bir sözleşme yayınlanmıştır. 190 sayılı "Çalışma Yaşamında Şiddet ve Tacizin Ortadan Kaldırılmasına İlişkin Sözleşme" başlıklı bu sözleşmeye göre üye ülkelerin ulusal hukuk ve şartlara uygun olarak, işçi ve işveren örgütlerine danışarak, çalışma yaşamında şiddet ve tacizin önlenmesi ve ortadan kaldırılması için kapsayıcı, bütünleşik ve toplumsal cinsiyete duyarlı bir yaklaşımını kabul etmesi şart koşulmaktadır (ILO, 2019, s.6).

İşyeri şiddetinin önlenmesine yönelik atılan adımlar ve hayata geçirilen uygulamalara ışık tutması açısından bu konuda yapılan bilimsel araştırmalar da büyük önem kazanmaktadır. Araştırmacıların işyeri şiddeti konusunda ortaya koyduğu farklı çalışmalar sayesinde çalışma ortamlarının 
daha güvenli olması sağlanabilmektedir. Tüm bunların yanında gün geçtikçe gelişen üretim ve hizmet sektörlerinin yenilenen yapılarında işyeri şiddetinin çok yönlü olarak değerlendirilmesi büyük önem taşımaktadır. Bu sayede özellikle örgütsel davranışlardan beklenen olumlu etkileşimin niteliği de daha fazla değer kazanabilecektir.

Bu çalışmanın amacı "işyeri şiddeti" ile ilgili alanyazında mevcut olan ana temaları belirlemek ve çalışma hayatında bu kavrama yönelik gelecek araştırma yönelimlerine katkı sağlayacak bir zemin hazırlamaktır. Bu amaç doğrultusunda çalışmada "işyeri şiddeti" ile ilgili yayınların bibliyometrik analizi yapılmıştır.

Belirli bir alanda yapılan çalışmaları bütüncül olarak kavrayabilmek için alanyazının sistematik şekilde taranması diğer araştırmacılara da yol gösterici olabilmektedir. Sistematik taramalarda nitel ve nicel yöntemler kullanılabilmektedir. Bu bağlamda bibliyometrik analiz seçeneği de kapsamlı ve karmaşık sistematik taramalarda tercih edilmeye başlanan dikkat çekici ve yenilikçi bir yöntemdir.

Pritchard (1969) tarafından istatistiksel bibliyografya yerine önerilen bibliyometri; bilimsel aktivitenin kapsamlı ölçümüne dayanan sistematik, şeffaf ve tekrarlanabilir bir inceleme süreci sunma potansiyeline sahiptir (Aria ve Cuccurullo, 2017, s.959). Bibliyometri sayesinde çeşitli dönemlerde yayınlanmış çok sayıda ve farklı türdeki bilimsel yayın veya doküman, belirli kriterler seçilerek sayısal yöntemler ile analiz edilebilmektedir (Köse ve ark., 2020; Osareh, 1996). Bu nedenle bibliyometrik araştırmalarda nitelikli literatür incelemelerinin yapılabilmesi için veri setlerinin özenli ve kasamlı şekilde oluşturulması önem taşımaktadır (Gürler, 2021; Şimşir, 2021).

Şiddete ilişkin yapılan bibliyometrik çalışmaların daha çok aile içi şiddet, akran zorbalığı, cinsel şiddet ve partner şiddeti alanında olduğu görülmektedir (Brilhante ve ark., 2016; López-Cepero ve FJ, 2009; Martins ve Nascimento, 2017; Moura ve ark., 2020; Wu ve ark. 2020). İşyeri şiddeti ile ilgili bibliyometrik bir çalışma ise Cebrino ve De la Cruz (2020) tarafından Scopus veri tabanı kullanılarak yalnızca sağlık çalışanlarına yönelik olarak yapılmıştır. 1992-2019 yıllarını kapsayan bu çalışmada 1791 adet sağlık işyeri şiddeti makalesi incelenmiştir (Cebrino ve De la Cruz 2020). Yapılan alanyazın taramasında çalışma hayatının tüm sektörlerinde yapılan işyeri şiddeti çalışmalarını kapsayan bibliyometrik bir analize ise rastlanmamıştır. Bu nedenle, bu çalışmanın söz konusu boşluğun doldurulmasına katkı sağlaya- 
cağı düşünülmektedir. Ayrıca çalışmanın işyeri şiddetine ait araştırmaların yönünü ve eğilimlerini göstermesi açısından ileride araştırma yapmayı düşünen araştırmacılara yol gösterebileceği düşünülmektedir.

\section{Yöntem}

Çalışma kapsamında işyeri şiddeti konusunda yayınlanan makalelerin bibliyometrik özelliklerinin belirlenmesi amaçlanmıştır. Çalışmanın anahtar kelimesi "workplace violence" şeklinde Web of Science (WoS) veri tabanında konu içeriği olarak taranmıştır. Araştırma kapsamına işyeri şiddeti konusunda yayınlanmış araştırma, derleme, kitap bölümü ve bidiri çalışmaları alınmıştır. İşyeri şiddeti yazınına ilişkin olarak 1994 yılı öncesinde herhangi bir makaleye rastlanmamıştır.

Yapılan bu çalışmada 1994-2020 yılları arasında yer alan 1393 adet makale bibliyometrik analiz ile incelenmiştir. Bu kapsamda öncelikle makalelerin yayın sınıfları ile yazar ve atıf sayılarına ait genel özellikler incelenmiştir. İşyeri şiddeti konusunda alanyazında en fazla atıf alan makalaler ise DOI numaraları ile birlikte sıralanmıştır. Yıllık yayın sayılarındaki değişikliklerin ve makalelerde geçen anahtar kelime yoğunluklarının gösterildiği şekillerin yanı sıra bu konudaki en ilgili dergi türlerine ve isimlerine de yer verilmiştir. Aynı zamanda işyeri şiddeti çalışmalarına en fazla katkı veren yazarların zaman içindeki üretimi ile ülkelerin atıf gücü ve atıf ağı da incelenmiştir. Bibliyometrik analiz sonuçları, Aria ve Cuccurullo (2017) tarafından geliştirilen "Bibliometrix" paket R programı ve ayrıca Eck ve Waltman (2010) tarafından geliştirilen VOSviewer yazılımları ile görselleştirilerek ortaya konulmuştur.

\section{Bulgular}

İşyeri şiddeti ile ilgili hazırlanan bibliyometrik çalışmada (Tablo 1), 19942020 yıllarına ait toplam 1393 makale WoS veri tabanı üzerinden elde edilmiştir. Bu makalelerin 1216 adeti araştırma, 37 adeti kitap bölümü, 13 adeti derleme, 28 adeti ise bildiri şeklinde yayınlanmıştır. 529 farklı yayın kaynağ üzerinden yayınlanan makaleleri toplamda 4207 yazar kaleme almıştır. Makale başına ortalama atıf sayısı 15,41'dir. Yazar başına düşen makale sayısı 0,331, makale başına düşen ortak yazar sayısı ise $4,15^{\prime}$ tir. 
Tablo 1. "İşyeri Şiddeti" Konulu Makalelerin Genel Özellikleri

\begin{tabular}{ll}
\hline İncelenen Yıllar & $1994-2020$ \\
\hline Araştırma & $1216(\% 87,3)$ \\
Derleme & $112(\% 8)$ \\
Kitap Bölümü & $37(\% 2,6)$ \\
Bildiri & $28(\% 2,1)$ \\
\hline Toplam Yayın & $1393(\% 100)$ \\
\hline Yayın Kaynağı & 529 \\
\hline Yazarların Anahtar Kelimeleri Sayısı & 2201 \\
\hline Makale Başına Ortalama Atıf & 15,41 \\
\hline Yıllık Ortalama Atıf & 1,8 \\
\hline Tek Yazarlı Makale & $140(\% 3,3)$ \\
Birden Fazla Yazarlı Makale & $4067(\% 96,7)$ \\
\hline Toplam Yazar Sayısı & $4207(\% 100)$ \\
\hline Yazar Başına Düşen Makale & 0,331 \\
\hline Makale Başına Düşen Ortak Yazar & 4,15 \\
\hline İşbirliği İndeksi & 3,3 \\
\hline
\end{tabular}

1994-2020 yılları arasinda incelenen 1393 makaleden en fazla atıf alan ilk 20 makale Tablo 2'de sıralanmıştır. Grandey ve arkadaşları (2004) tarafından yazılan "Müş̧teri her zaman haklı değildir: müşteri saldırganlığı ve hizmet çalışanlarının duygu düzenlemesi" başlıklı makale, işyeri şiddeti konusunda en fazla atıf alan çalışma olmuştur. Neuman ve Baron (1998), işyerinde şiddet ve saldırganlık konulu çalışmalarında ilgili kanıtlara, olası nedenlere ve şiddeti önlemeye yönelik hedeflere yer vermiştir. Penny ve Spector (2005) ise iş stresi, kabalık ve verimsiz iş davranışı üzerinde bir çalışma yapmıştır. Bu çalışma sonucuna göre genel olarak iş stresörleri ve verimsiz iş davranışı arasındaki ilişkilerin olumsuz duygulanımı yüksek olan bireyler için olumsuz duygulanım düzeyi düşük olanlara göre daha güçlü olduğu ortaya çıkmıştır.

\section{Tablo 2. "İşyeri Şiddeti" Konusunda En Fazla Alıntı Yapılan Makaleler}

\begin{tabular}{|c|c|c|}
\hline Yazar, Yll, Yayın & Makale, DOI & Atıf \\
\hline $\begin{array}{l}\text { GRANDEY AA, 2004, } \\
\text { J ORGAN BEHAV }\end{array}$ & $\begin{array}{l}\text { The customer is not always right: customer aggression and emotion } \\
\text { regulation of service employees / } 10.1002 / \text { job. } 252\end{array}$ & 390 \\
\hline $\begin{array}{l}\text { NEUMAN JH, 1998, } \\
\text { J MANAGE }\end{array}$ & $\begin{array}{l}\text { Workplace Violence and Workplace Aggression: Evidence Concer- } \\
\text { ning Specific Forms, Potential Causes, and Preferred Targets / } \\
\underline{10.1177 / 014920639802400305}\end{array}$ & 384 \\
\hline $\begin{array}{l}\text { PENNEY LM, 2005, } \\
\text { J ORGAN BEHAV }\end{array}$ & $\begin{array}{l}\text { Job stress, incivility, and counterproductive work behavior (CWB): } \\
\text { the moderating role of negative affectivity / } 10.1002 / j \mathrm{job} .336\end{array}$ & 374 \\
\hline $\begin{array}{l}\text { BARON RA, 1996, } \\
\text { AGGRESSIVE BEHAV }\end{array}$ & $\begin{array}{l}\text { Workplace Violence and Workplace Aggression: Evidence on Their } \\
\text { Relative Frequency and Potential Causes / 10.1002/(SICI)1098- } \\
\text { 2337(1996)22:3<161::AID-AB1>3.0.CO;2-Q }\end{array}$ & 322 \\
\hline $\begin{array}{l}\text { LEBLANC MM, 2002, } \\
\text { J APPL PSYCHOL }\end{array}$ & $\begin{array}{l}\text { Predictors and Outcomes of Workplace Violence and Aggression / } \\
10.1037 / 0021-9010.87 .3 .444\end{array}$ & 238 \\
\hline SPECTOR PE, 2014, & Nurse exposure to physical and nonphysical violence, bullying, and & 224 \\
\hline
\end{tabular}




\begin{tabular}{|c|c|c|}
\hline INT J NURS STUD & $\begin{array}{l}\text { sexual harassment: A quantitative review } \\
\text { / 10.1016/j.ijnurstu.2013.01.010 }\end{array}$ & \\
\hline $\begin{array}{l}\text { ROCHE M, 2010, } \\
\text { J NURS SCHOLARSHIP }\end{array}$ & $\begin{array}{l}\text { Violence Toward Nurses, the Work Environment, and Patient } \\
\text { Outcomes / 10.1111/j.1547-5069.2009.01321.x }\end{array}$ & 220 \\
\hline $\begin{array}{l}\text { SURIS A, 2008, } \\
\text { TRAUMA VIOLENCE ABUS }\end{array}$ & $\begin{array}{l}\text { MILITARY SEXUAL TRAUMA A Review of Prevalence and Associ- } \\
\text { ated Health Consequences in Veterans } \\
/ \underline{10.1177 / 1524838008324419}\end{array}$ & 218 \\
\hline $\begin{array}{l}\text { GATES DM, 2011, } \\
\text { NURS ECON }\end{array}$ & $\begin{array}{l}\text { Violence against nurses and its impact on stress and productivity / } \\
\text { PMID: } 21667672\end{array}$ & 217 \\
\hline $\begin{array}{l}\text { FNAIS N, 2014, } \\
\text { ACAD MED }\end{array}$ & $\begin{array}{l}\text { Harassment and Discrimination in Medical Training: } \\
\text { A Systematic Review and Meta-Analysis } \\
\text { /10.1097/ACM.0000000000000200 }\end{array}$ & 198 \\
\hline
\end{tabular}

İncelenen dönem (Şekil 1) içerisindeki ilk 3 yıl için; 1994'te 3, 1995'te 6, 1996'da 23 olan makale sayısı, 1997 ila 2006 yılları arasında durağan bir seyir izlemiştir. Son 5 yılda hızlı bir şekilde artan yayınlar, 2016' da 105, 2017'de $125,2018^{\prime}$ de 166,2019 'da 200 olurken, 2020 yılında ise $223^{\prime}$ e ulaşmıştır.

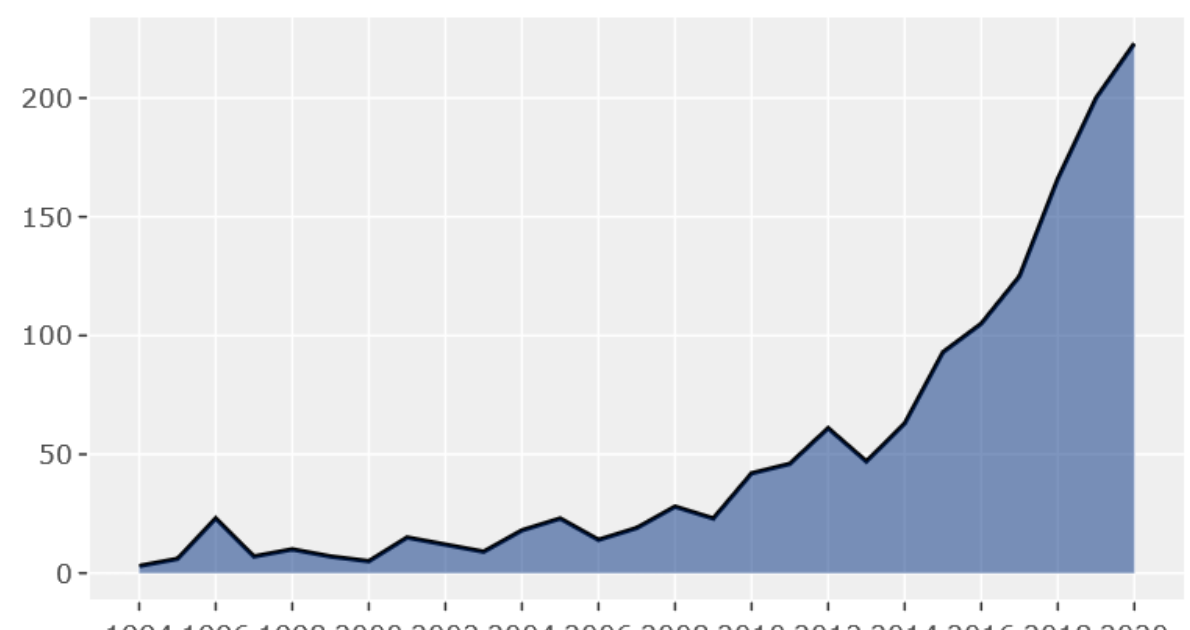

19941996199820002002200420062008201020122014201620182020

Şekil 1. "İşyeri Şiddeti” Konulu Makalelerin Yıllık Yayın Sayısı

Keywords Plus, WoS'a özel ve atıf yapılan makalelerin başlıklarından alınan kelimelerden veya ifadelerden oluşan bir sistemdir. Bu sinıflandırmaya göre makalelerin anahtar kelimeleri incelendiğinde "saldırganlık", "hemşireler", "çalışma”, "personel”, "stres", "risk faktörleri", “etki”, "yaygınlık", "hasta" ve "sağlık" gibi kavramların "işyeri şiddeti" kavramıla birlikte sıklıkla kullanıldığı görülmektedir (Şekil 2). 


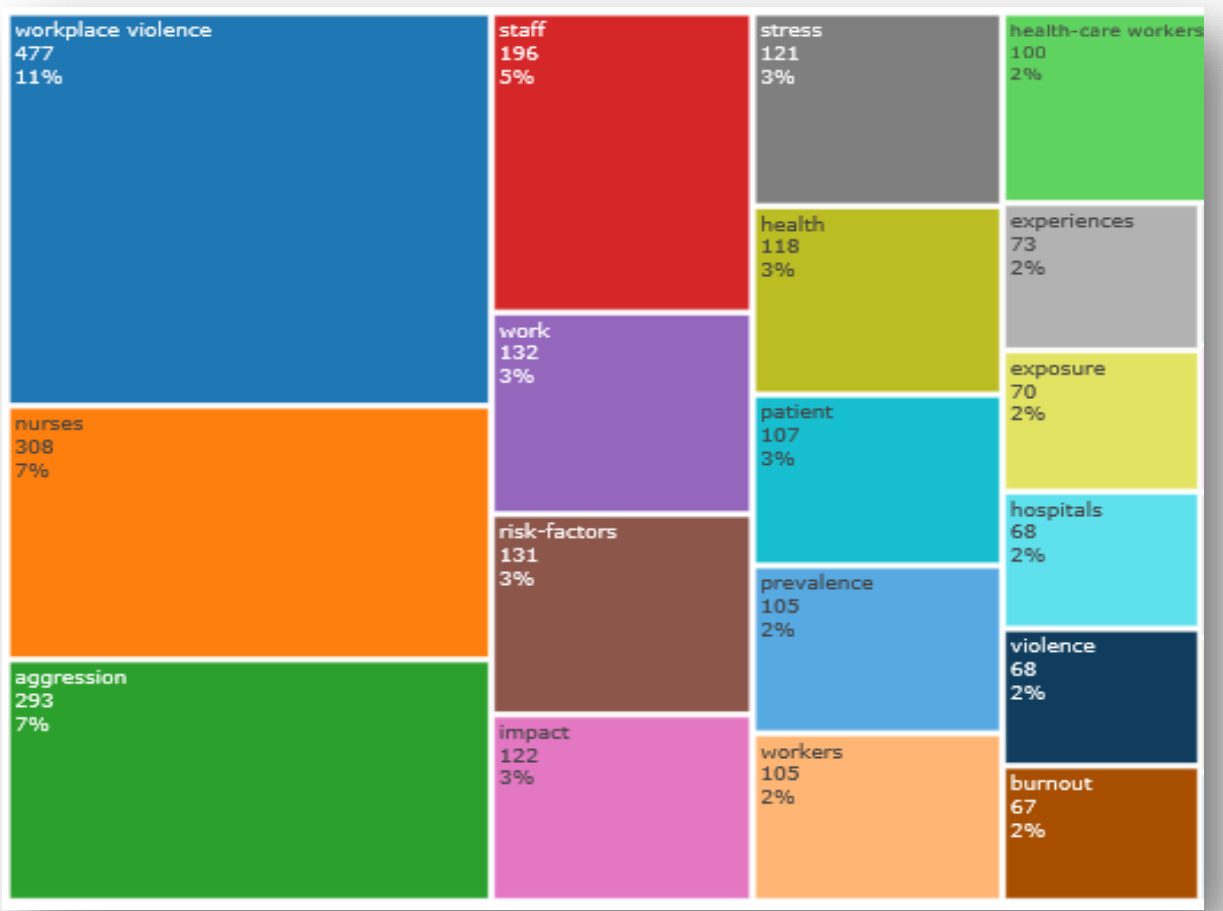

Şekil 2. "İşyeri Şiddeti" Konulu Makalelerin Anahtar Kelime Oranları

İşyeri şiddeti konusuna en fazla yer veren dergi türlerinin \%23,5 oranında hemşirelik, \%21,69 oranında halk, çevre ve iş sağlığı, \%6,47 oranında adli tıp ve \%6,24 oranında ise psikiyatri alanlarının olduğu saptanmıştır (Şekil 3). Grafikten de anlaşılacağı gibi bu konuda yüksek oranda sağlık alanındaki dergi türlerinin etkili olduğu görülmektedir. 


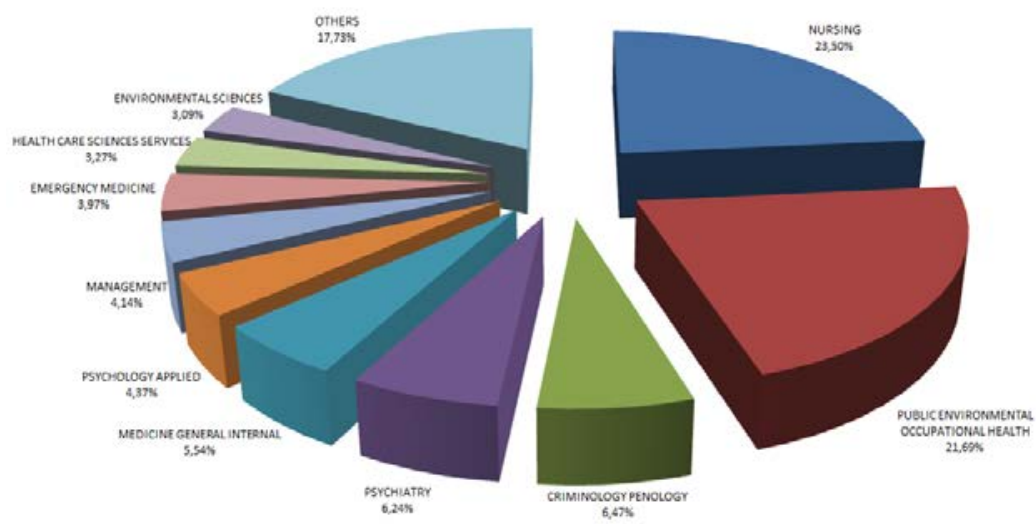

Şekil 3. Türlerine Göre "İşyeri Şiddeti" Konusuna Yer Veren Dergiler

İşyeri şiddeti konusuna yer veren en fazla makalenin 40 yayın sayısı ile "INTERNATIONAL JOURNAL OF ENVIRONMENTAL RESEARCH AND PUBLIC HEALTH" dergisine ait olduğu görülmektedir. Bu dergiyi 37 yayın sayısı ile "WORK-A JOURNAL OF PREVENTION ASSESSMENT \& REHABILITATION" dergisi takip ederken, ardından 34 yayın sayısı ile "AMERICAN JOURNAL OF INDUSTRIAL MEDICINE" dergisi gelmektedir. Yayın türlerine bakıldığında ise hemşirelik dergilerinin işyeri şiddeti konusuna genel anlamda ilgi gösterdiği anlaşılmaktadır (Şekil 4).

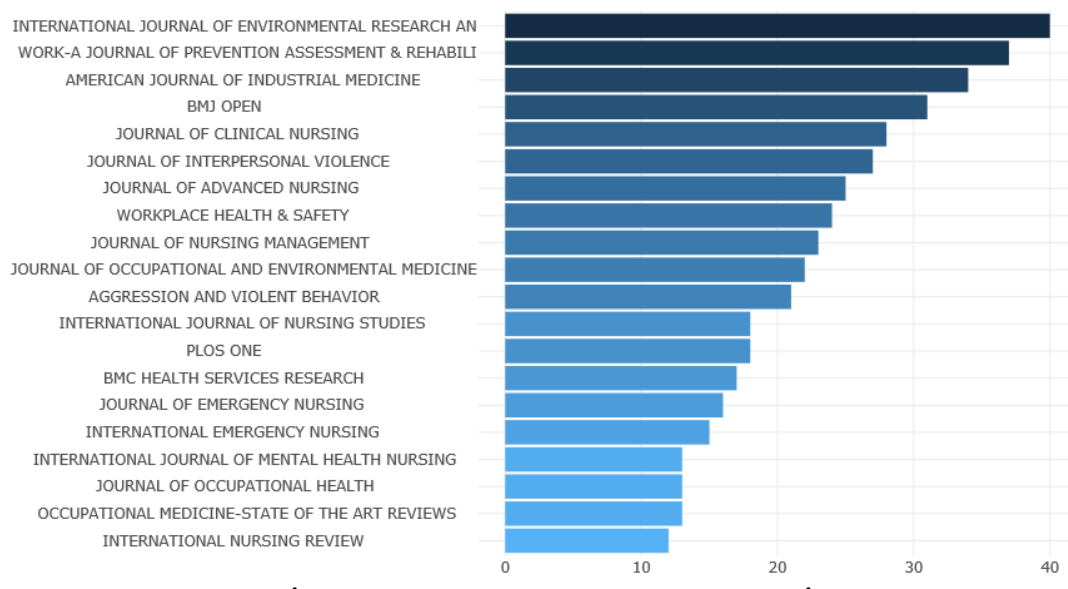

Şekil 4. "İşyeri Şiddeti” Konulu Makalelerle En İlgili Dergiler 
İşyeri şiddeti konusunda en çok yayın yapan 20 ülkenin uluslararası işbirliği derecesi incelenmiştir (Şekil 5). SCP; ülkenin kendi içindeki üretimi anlamına gelirken, MCP ise birden fazla ülkenin işbirliği ile yapılan üretimi anlamına gelmektedir. Buna göre ABD'nin 463 yayın ile en fazla üretim yapan ülke olduğu görülse bile $\mathrm{MCP}$ işbirliği oranının ancak \%8 olduğu anlaşılmaktadır. Oysaki işyeri şiddeti konusunda toplamda 137 yayını olan Çin'in \%30 MCP işbirliği oranı ile ilk sırada yer aldığı ortaya çıkmaktadır. Çin'i \%29 MCP işbirliği oranı ile Ürdün, \%28 ile İrlanda, \%27 ile Fransa, \%26 ile İtalya ve \%25 ile İran takip etmektedir. Toplamda 42 yayını olan Türkiye'nin MCP işbirliği oranının ise \%9,5 olduğu saptanmıştır.

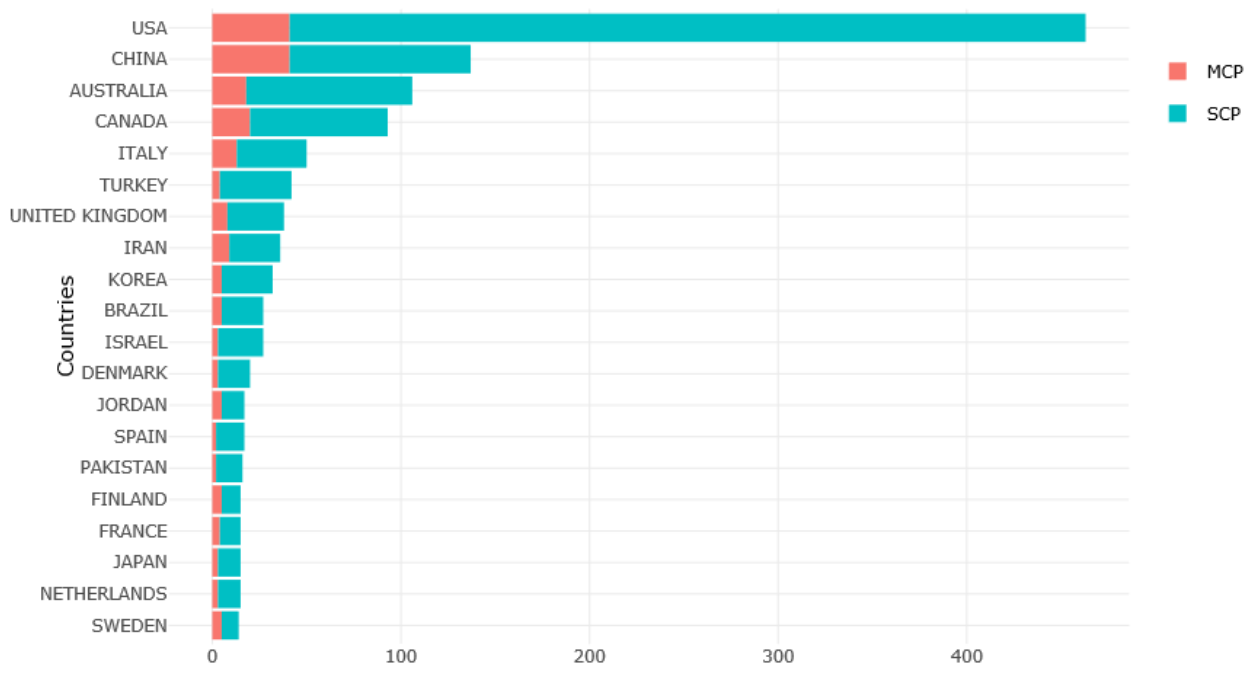

Şekil 5. “íşyeri Şiddeti” Konulu Makalelerin Uluslarası İşbirliği Derecesi

İşyeri şiddeti konusunda yazılan makalelerin ülkelere göre atıf gücü ve atıf ağı incelenmiş̧tir. Toplam 88 ülkenin katkı sağladığı alanyazın için en az 5 ve üzeri makale yayınlayan 39 ülke değerlendirmeye alınmıştır (Şekil 6). Bu kapsamda ülkelere göre atıf analizi görsel haritalaması incelendiğinde birbiri ile etkileşim içinde olan dört adet kümenin varlığı ortaya çımaktadır. Kümeyi oluşturan kurumlar arasındaki ilişki mavi, kırmızı, sarı ve yeşil renklerle gösterilmiştir. 11 ülkeden oluşan mavi renkli kümede ABD'nin başat ülke olduğu, 16 ülkeden oluşan kırmızı renkli kümede Çin ve Avustralya'nın başat ülkeler olduğu, 9 ülkeden oluşan yeşil renkli kümede İtalya'nın başat ülke olduğu, 3 ülkedden oluşan sarı renkli kümede ise Kana- 
da'nın başat ülke olduğu ortaya çıkmıştır. Değerlendirmeye alınan tüm ülkeler içinde ise ABD'nin 9338 atıf ve 3573 bağlantı gücü sayısı ile birinci sırada olduğu görülmektedir. ABD'yi; 2330 atıf ve 1772 bağlantı gücü sayısı ile Avustralya, 1400 atıf ve 1276 bağlantı gücü sayısı ile Çin izlemiştir.

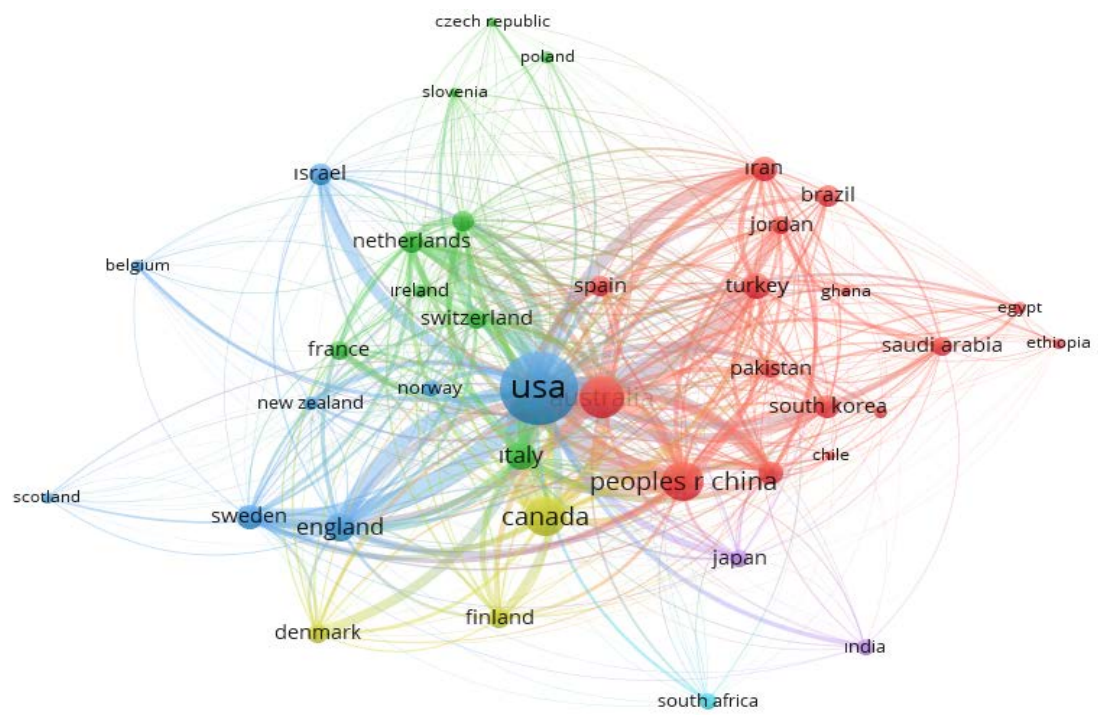

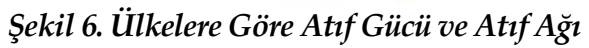

Yazarların üretim sürecine bakıldığında Arnetz ve Gates'in işyeri şiddeti konusunu ele alan ilk yazarlar arasında olduğu görülmektedir (Şekil 7). Şekil 7.'nin içinde yer alan yuvarlak şekillerin büyüklüğü ve koyuluğu yayınların atıf gücünü göstermektedir. Buna göre; Jiao, Wu, Fan ve Li ise son dönemde katkı sağladıkları çalışmlarıyla bu alanda yüksek düzeyde atıf almalarıyla dikkat çekmektedir. Peek-Asa ve Casteel'in atıf gücü yüksek olmasa bile uzun süre ve sık aralıklarla alanyazına katkı sağladığı anlaşımaktadır. 


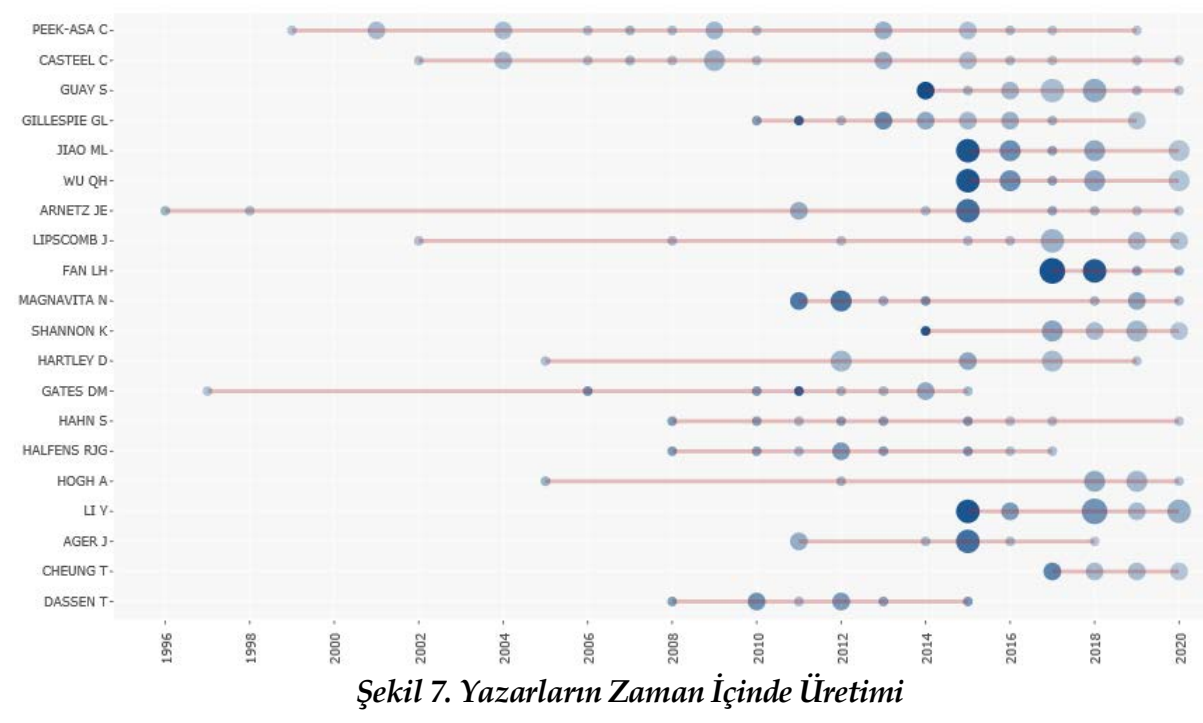

ABD'den Wayne State Üniversitesi ve Çin'den Harbin Medical Üniversitesi üyelerinin işyeri şiddeti konusunda yoğun çalışma içinde oldukları görülmektedir (Şekil 8). Çalışmalarda yararlanılan kaynakların ise genel olarak 2001-2014 yıllarında sağlık hizmetleri, tıp ve hemşirelik alanındaki dergi yazarlarına ait olduğu anlaşılmaktadır. Bu sayede yazılan yeni makaleler de yine benzer türdeki dergilerde yayınlanmaktadır.

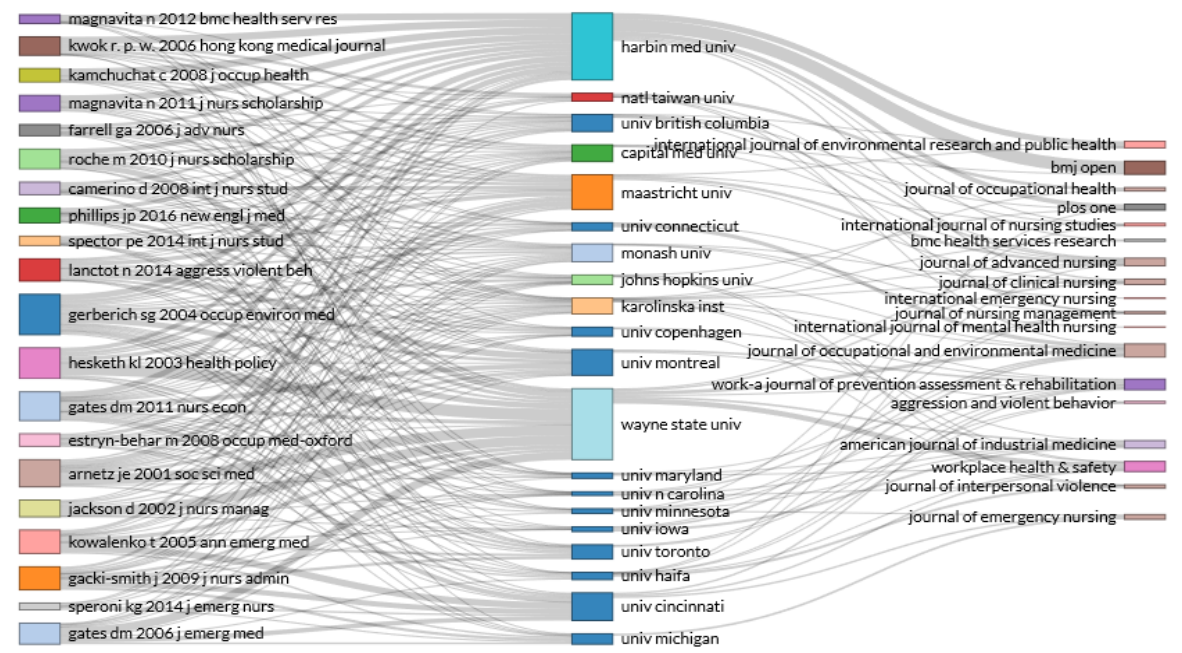

Şekil 8. Kaynak, Kuruluş ve Yayın İlişkili Üç Alan Grafiği 
Çalışmaya alınan tüm makalelerin özetleri üzerinden işyeri şiddeti araştırmalarının eğilim konuları analiz edilmiştir (Şekil 9). Buna göre başlangıçta işyeri şiddetinin nedenleri ve sonuçları üzerinde dar bir alanda ve az sayıda çalışma yapıldığı görülmektedir. İlerleyen yıllarda ise işyeri şiddetinin türlerine ve alanlarına göre çalışmaların olduğu anlaşılmaktadır. 2015-2020 yıllarında ise işyeri şiddeti konusunda tüm zamanlara göre çok daha fazla makale yayınlanmasına rağmen, bu çalışmaların büyük bir kısmının sağlık sektöründe ve örgütsel davranışlarla ilişkili olduğu söylenebilir.

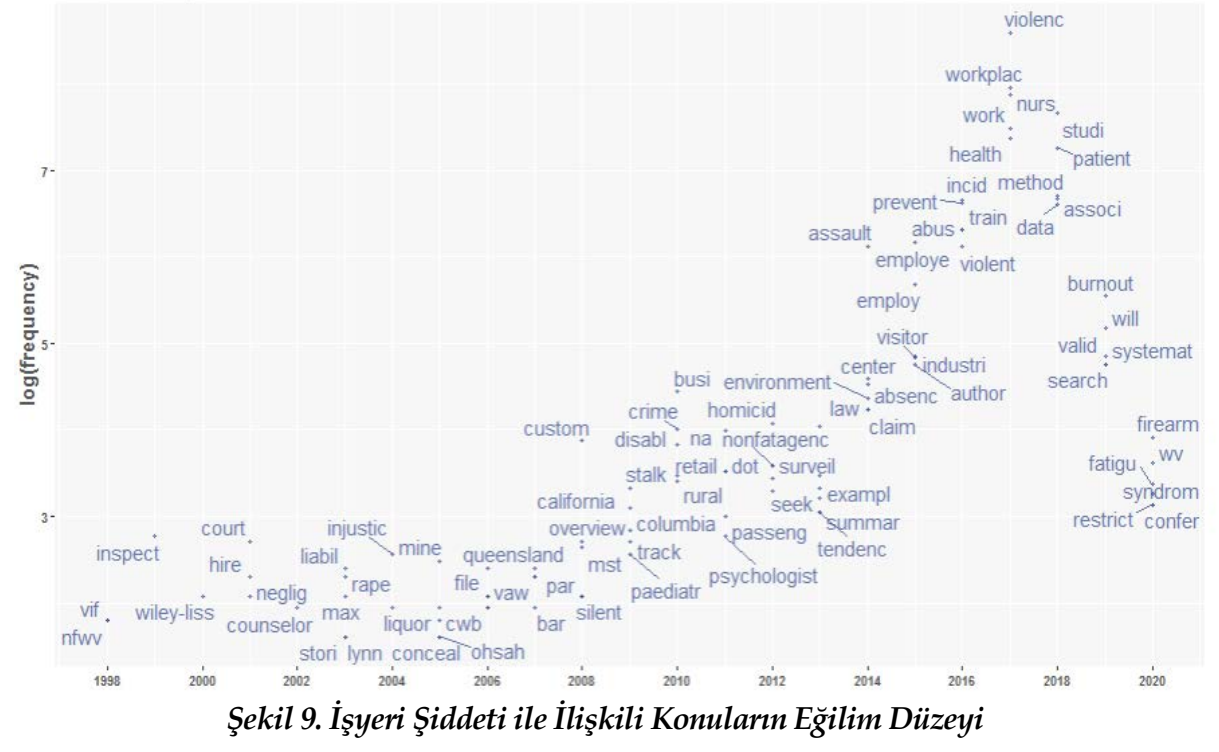

\section{Sonuç}

İşyeri şiddeti, bireyde ve örgütlerde ortaya çıkan olumsuz sonuçlarıyla günümüzde artık uluslararası ölçekte ele alınan ve çözüm üretilmeye çalışılan bir sorun olarak karşımıza çıkmaktadır. Bu nedenle işyeri şiddeti kavramı dikkat çekici boyutlara ulaşan yaygınlığı nedeniyle araştırmacılar için de ayrı bir çalışma alanı haline gelmiştir. Alanyazında mevcut olan ana temaları belirlemek ve gelecek araştırma yönelimlerine katkı sağlamak amacıyla yapılan bu çalışmada "işyeri şiddeti" ile ilgili yayınların bibliyometrik analizi yapılmıştır.

Çalışmanın niteliği açısından; işyeri şiddetinin bibliyometrik analizi, WoS veri tabanı üzerinden incelenmiştir. Bu veri tabanı yüksek kaliteli der- 
gilerin, kitap bölümlerinin ve konferans bildirilerinin güvenilir bir koleksiyonu olarak kabul edilmektedir. Bibliyometrik analiz sonuçları, son dönem uygulamalarından R programı ve VOSviewer yazılımları ile ayrıca görselleştirilmiştir. Bu sayede yüksek sayıdaki karmaşık verilerin okuyucu tarafından daha kolay yorumlanabilmesi sağlanmıştır.

Bu çalışmada 1994-2020 yıllarına ait İngilizce dilindeki makale türünde "işyeri şiddeti (workplace violence)" kavramı taranarak, 88 farklı ülkeden bu konuya değinen 1393 makale tespit edilmiştir. 23 adet İspanyolca, 12 adet Fransizca, 10 adet Almanca, 9 adet İtalyanca, 6 adet Korece, 5 adet Türkçe, 4 adet Portekizce, 3 adet İsveççe, 1 adet Katalanca, 1 adet Macarca ve 1 adet Farsça makale ise analiz içeriğindeki terminolojik yapıya uyumsuz olabileceği gerekçesiyle kapsam dişında bırakılmıştır. İşyeri şiddeti konusunun farklı ülkelerde, bu çeşitlilikte ve ulusal dil düzeyinde inceleniyor olması ise, sorunun tüm ülkelerdeki yaygınlı̆̆ı açısından ayrıca dikkat çekici bir durum olarak görülebilir.

Kullanılan araştırma yöntemleri bakımından incelendiğinde, işyeri şiddeti yayınları için araştırmacılar tarafından çoğunlukla nicel araştırma tekniklerinin tercih edildiği görülmektedir. Bu teknik kapsamında gerçekleştirilen 1216 araştırma makalesinin genel olarak anket yöntemi ile toplanan veriler sayesinde yapıldığı görülmektedir. Bu çalışmada da görüldüğü gibi özellikle sosyal bilimlerde yapılan araştırmalarda en sık kullanılan veri toplama yönteminin anket yöntemi olduğu bilinmektedir. Anket yönteminin tüm zorluklarına rağmen popülasyonlar hakkında veri toplamak ve çıkarım yapmak için en etkili yöntem olduğu kabul edilmektedir (Couper, 2017).

Yapılan çalışmada işyeri şiddeti konulu toplam 1393 makalenin tek yazarlı oranı \%11 olurken, ortak yazarlı oranı ise \%89 olarak saptanmıştır. Şiddet türleri ile ilgili sınırlı sayıda yapılan bibliyometrik çalışmalarda benzer şekilde ortak yazar oranlarının ülkelere göre \%80-90 aralığında olduğu görülmektedir (Cebrino ve De la Cruz 2020; Wu ve ark. 2020).

Yapılan analizlerde en fazla atıf alan ilk 5 makalenin 1996-2005 yılları arasında olması dikkat çekicidir. Bu durumu daha sağlıklı yorumlamak için başka bir analizi de göz önünde bulundurmak gerekir. Bahsedilen dönemler, işyeri şiddeti makalelerinin en durağan süreçlerini yaşadığı dönemlerdir. Oysaki 2008 ila 2020 yılları arasında sürekli artan makale sayısı için önceki dönemlerdeki çalışma kısıtılılığın söz konusu yazarlara atıf avantajı sağladığı söylenebilir. 
İncelenen dönem içerisinde ilk 3 y1l için; 1994'te 3, 1995'te 6, 1996'da 23 olan makale sayısı, 1997 ila 2006 yılları arasında durağan bir seyir izlemiştir. Son 5 yılda hızlı bir şekilde artan yayınlar, 2016'da 105, 2017' de 125, 2018'de 166,2019 'da 200 olurken, 2020 yllında ise 223'e ulaşmıştır.

İşyeri şiddeti konusuna en fazla yer veren dergi türlerinin \%75 oranında sağlık alanı ile ilgili olduğu görülmektedir. Her ne kadar sağlık işyeri ortamında yaşanan şiddetin bu oranı artırmada başat neden olduğu kabul edilse bile yeterli bir görüş olmayabilir. İşyeri şiddeti nedeniyle ortaya çıan olumsuzlukların aynı zamanda bir sağlık sorunu olması, bu tür dergiler için ayrıca bir çalışma alanı olarak kabul edilebilir. Bu nedenle işyeri şiddeti konulu makalelerin başlica anahtar kelimeleri arasında "hemşireler", "hasta", "stres", "anksiyete" ve "akıl sağlı̆̆ı" gibi terimlerin sıklıkla karşımıza çıkması doğal kabul edilmelidir.

"İşyeri şiddeti" ile ilgili en fazla çalışmanın yapıldığı ülkeler; ABD, Çin, Avustralya, Kanada, İtalya ve Türkiye'dir. Yazılan makalelerin ülkelere göre atıf gücü ve atıf ağı incelendiğinde ise ABD'nin 9338 atıf ve 3573 bağlantı gücü sayısı ile birinci sırada olduğu görülmektedir. Ülkelerin atıf sayısı ve bağlantı gücü, makale üretim sayısı ile uyumlu olarak sıralanmaktadır. Bu bağlamda; işyeri şiddeti konusunda ne kadar fazla bilimsel yayın üretilirse atıf alma oranının da o denli artabilceği söylenebilir. Bu çalışmaya benzer şekilde sağlık işyeri şiddeti ve diğer şiddet türleri konusunda yapılan bibliyometrik çalışmalarda da ABD'nin en fazla yayın üreten ülke olduğu belirtilmiştir (Aria ve Cuccurullo 2017; Brilhante ve ark. 2016; Cebrino ve De la Cruz 2020).

Yapılan çalışmaya ilişkin bazı sınırılıklar bulunmaktadır. 22.02.2021 tarihinde elde edilen verilerle yapılan çalışmaya 2020 yılı sonrasındaki makaleler dahil edilmemiştir. Bu nedenle, 1 Ocak 2021 tarihli ve sonrası WoS veri tabanına eklenen yeni makaleler ile elde edilecek veriler analizlerde farklılık oluşturabilecektir. Çalışmada seçilen yayınlar; yalnızca WoS veri tabanında yer alan İngilizce dilindeki makalelerden oluşmaktadır. Gelecekte benzer çalışmalar yapmak isteyen araştırmacılara; işyeri şiddetine ilişkin yayın türlerini, dillerini ve indekslerini genişleterek daha kapsamlı analizler yapmaları önerilebilir. Bu bağlamda farklı sektörlerdeki çeşitli türdeki işyeri şiddetine yönelik araştırmalara odaklanılabilir. Siber şiddet gibi teknolojik gelişmelerden kaynaklı nedenler de dikkate alınarak, işyeri şiddetinin güncel ve niş alanlarına yönelik çalışmalar ayrıntılı şekilde incelenebilir. 


\section{EXTENDED ABSTRACT}

\section{Bibliometric Analysis of Workplace Violence Studies \\ Fatih Seyran \\ Republic of Turkey Ministry of Health}

Workplace violence has become a separate field of study with its remarkable results. Today, millions of employees who provide different services in many sectors such as public order, accommodation, transportation, education and health in different parts of the world are subject to violence from time to time. Many employees around the world are abused, threatened, attacked or subjected to other aggressive behaviors in situations related to their work (Di Martino and Musri, 2001, p.7). Violence can occur against employees in work environments in various sectors in all countries. Employees are victims of murder, rape, and even being held hostage for reasons such as robbery, theft, and extortion in their workplaces or in different environments related to their jobs (Çakır, 2010; Rugala and Isaacs, 2003; Tian et al., 2020). Various forms of aggressive behavior such as punching, kicking, slapping, harassing, spitting, bullying, blackmail, discrimination, threatening, intimidation, rude, swearing, shouting, humiliating, slang, sexual harassment, etc. behaviors can be seen in workplaces (Chappell and Di Martino, 2006; Duhart, 2001; Rugala and Isaacs, 2003; Yıldız et al., 2011).

Workplace violence is now seen as an international problem and a solution is tried to be found. For example; International Labor Organization (ILO), which has 185 member countries, published an agreement in 2019 that sets international standards to prevent violence and harassment in the business world. According to the "Convention on the Elimination of Violence and Harassment in Working Life" No. 190, an inclusive, integrated and gender-sensitive regulation was encouraged in consultation with workers 'and employers' organizations in accordance with the national laws and conditions (ILO, 2019, p.6).

The aim of this present study is to determine the main themes existing in the literature regarding "workplace violence" and to prepare a ground that will contribute to future research orientations towards this concept in busi- 
ness life. In line with this purpose, bibliometric analysis of publications on "workplace violence" was made.

Within the scope of this study conducted with bibliometric analysis method, the concept of "workplace violence" was scanned in the English article type from 1994-2020, and 1393 articles from 88 different countries addressing this issue were identified. In the study, the rate of a total of 1393 articles on workplace violence with a single author was $11 \%$, while the rate of co-authors was $89 \%$. Similarly, in a limited number of bibliometric studies on violence types, it is seen that the rate of co-authors is between $80-90 \%$ according to countries (Cebrino and De la Cruz, 2020; Wu et al., 2020). The first 5 articles with the most citations in the analysis conducted are included in the years 1996-2005. For the first 3 years within the period examined; The number of articles, which was 3 in 1994, 6 in 1995, and 23 in 1996, followed a stable course between 1997 and 2006. The publications that have increased rapidly in the last 5 years have reached 105 in 2016, 125 in 2017, 166 in 2018, 200 in 2019, and 223 in 2020. It is observed that $75 \%$ of the journal types that cover the issue of workplace violence most are related to the field of health. Countries with the most studies on "workplace violence"; USA, China, Australia, Canada, Italy and Turkey. When the citation power and citation network of the articles written by countries are examined, it is seen that the USA is in the first place with 9338 citations and 3573 connection power.

\section{Kaynakça / References}

Antão, H. S., Sacadura-Leite, E., Manzano, M. J., Pinote, S., Relvas, R., ve Florentino Serranheira, A. S.-U. (2020). Workplace violence in healthcare: A single-center study on causes, consequences and prevention strategies. Acta Médica Portuguesa, 33(1), 31-37. DOI: 10.20344/amp.11465

Aria, M., ve Cuccurullo, C. (2017). Bibliometrix: An r-tool for comprehensive science mapping analysis. Journal of Informetrics, 11(4), 959-975. DOI: 10.1016/j.joi.2017.08.007

Arın, C. (1996). Kadına yönelik şiddet. Cogito, 6-7(Kış-Bahar), 305-312.

Aydemir, İ., Üçlü, R., ve Aydoğan, A. (2020). Acil servis personeline göre şiddetin nedenleri. İstanbul Tip Fakültesi Dergisi, 83(1), 60-68. DOI: 10.26650/iuitfd.2019.0018 
Brilhante, A. V. M., Moreira, G. A. R., Vieira, L. J. E. de S., ve Catrib, A. M. F. (2016). A bibliometric study on gender violence. Saúde e Sociedade, 25(3), 703-715. DOI: 10.1590/S0104-12902016148937

Çakır, A. (2010). Suç gelirlerinin aklanması ve terörizmin finansmanının engellenmesi: Banka riskleri ve uyum programının oluşturulması. Bankaclar Dergisi, 21(74), 69-73.

Cebrino, J., ve De la Cruz, S. P. (2020). A worldwide bibliometric analysis of published literature on workplace violence in healthcare personnel. PLOS ONE, 15(11), 116. DOI: 10.1371 /journal.pone.0242781

Chappell, D., ve Di Martino, V. (2006). Violence at Work. In International Labour Organization, 4. International Labour Organization.

Choi, S., ve Lee, H. (2017). Workplace violence against nurses in Korea and its impact on professional quality of life and turnover intention. Journal of Nursing Management, 25, 508-518. DOI: 10.1111/jonm.12488

Couper, M. P. (2017). New developments in survey data collection. Annual Review of Sociology, 43, 121-145. DOI: 10.1146/annurev-soc-060116-053613

Di Martino, V., ve Musri, M. (2001). Guidance for the prevention of stress and violence at the workplace. In Ministry of Human Resources Malaysia and International Labour Organization.

Duan, X., Ni, X., Shi, L., Zhang, L., Ye, Y., Mu, H., Li, Z., Liu, X., Fan, L., ve Wang, Y. (2019). The impact of workplace violence on job satisfaction, job burnout, and turnover intention: The mediating role of social support. Health and Quality of Life Outcomes, 17(93), 1-10. DOI: 10.1186/s12955-019-1164-3

Duhart, D. T. (2001). Violence in the workplace, 1993-99. In Bureau of Justice Statistics.

Eck, N. J. Van, and Waltman, L. (2010). Software survey: VOSviewer, a computer program for bibliometric mapping. Scientometrics, 84(2), 523-538. DOI: 10.1007/s11192-009-0146-3

Gözlü, M. (2020). İş ilişkileri ve toplu pazarlık., K. (Ed.). Sağlık Sektöründe Insan Kaynakları Yönetimi, içinde (s. 347-392).Ankara: Gazi Kitabevi,

Gürler, G. (2021). Bibliyometrik araştırmalarda ilgili litaretüre ilişkin veri setinin oluşturulma süreci., O. Öztürk ve G. Gürler (Ed.). Bir Literatür İncelemesi Aracı Olarak Bibliyometrik Analiz. içinde (s. 53-66). Ankara: Nobel Bilimsel Eserler, ISBN: 978-625-7363-30-3

Hamlin, L., and Hoffman, A. (2002). Perioperative nurses and sexual harassment. AORN Journal, 76(5), 855-860. 
Hıdıroğlu, S., Tanriöver, Ö., Tosun, M., Turan, C. A., Günaydın, B. S., Eser, B., Htoo, K. M., ve Karavuş, M. (2019). Birinci basamak sağlık çalışanlarının şiddete maruziyet düzeyleri ile iş doyumu arasındaki ilişkinin değerlendirilmesi. The Journal of Turkish Family Physician, 10(4), 173-184. DOI: 10.15511/tjtfp.19.00473

International Labour Conference. (2019). Convention 190. https://www.ilo.org/ilc/ILCSessions/108/reports/textsadopted/WCMS_711570/lang--en/index.htm

Kale, E., Salim, B., Baytok, Y., Tortumluoğlu, S., Küçük, A., ve Eraslan, M. (2020). Hastanelerde hizmet alım personellerine yönelik şiddet olaylarının değerlendirilmesi. Sağlıkta Performans ve Kalite Dergisi, 16(1), 83-119.

Köse, G., Kurutkan, M. N., ve Orhan, F. (2020). Kalp yetmezliği konusunda en çok atıf alan ilk 100 makalenin bibliyometrik analizi. Sağlık Akademisyenleri Dergisi, 7(2), 92-104.

Lanctot, N., ve Guay, S. (2014). The aftermath of workplace violence among healthcare workers: A systematic literature review of the consequences. Aggression and Violent Behavior, 19(5), 492-501. DOI: 10.1016/j.avb.2014.07.010

Li, N., Zhang, L., Xiao, G., Chen, J., and Lu, Q. (2019). The relationship between workplace violence, job satisfaction and turnover intention in emergency nurses. International Emergency Nursing, 45, 50-55. DOI: 10.1016/j.ienj.2019.02.001

Liu, W., Zhao, S., Shi, L., Zhang, Z., Liu, X., Li, L., Duan, X., Li, G., Lou, F., Jia, X., Fan, L., Sun, T., ve Ni, X. (2018). Workplace violence, job satisfaction, burnout, perceived organisational support and their effects on turnover intention among Chinese Nurses in Tertiary Hospitals: A cross-sectional study. BMJ Open, 8(6), 111. DOI: 10.1136/bmjopen-2017-019525

López-Cepero, J., and FJ, R. D. (2009). Domestic violence: A Bibliographic and Bibliometric Review. Psicothema, 21(2), 248-254.

Martino, V. di. (2002). Workplace violence in the health sector. Country case studies Brazil, Bulgaria, Lebanon, Portugal, South Africa, Thailand and an additional Australian study. https://www.who.int/violence_injury_prevention/violence/activities/workplace/ WVsynthesisreport.pdf?ua $=1$

Martins, A. G., ve Nascimento, A. R. A. do. (2017). Domestic violence, alcohol and other associated factors: A bibliometric analysis. Arquivos Brasileiros de Psicologia, 69(1), 107-121.

Moura, L. K. B., Azevedo, U. N. de, Wingerter, D. G., Ferreira, M. A. F., Maciel, M. P. R., Moura, R. P., Silva, A. M. da, ve Alves, M. do S. C. F. (2020). Bibliometric analysis of the scientific evidence on violence perpetrated against the elderly. Ciência and Saúde Coletiva, 25(6), 2143-2152. 
Neuman, J. H., ve Baron, R. A. (1998). Workplace violence and workplace aggression: Evidence concerning specific forms, potential causes, and preferred targets. Journal of Management, 24(3), 391-419. DOI: 10.1177/014920639802400305

Osareh, F. (1996). Bibliometrics, citation analysis and co-citation analysis: A review of literature 1. Libri, 46(3), 149-158. DOI: 10.1515/libr.1996.46.3.149

Öztürk, Y. E., Kıraç, F. Ç., ve Yılmazsoy, B. (2018). Sağlık çalışanlarında işyeri şiddetinin iş dorumu ve örgütsel bağlllık üzerine etkisi. 2. Uluslararası 12. Ulusal Sağhlk ve Hastane İaresi Kongresi.

Parent-Thirion, A., Macías, E. F., Hurley, J., ve Vermeylen, G. (2007). Fourth European working conditions survey. In European Foundation for the Improvement of Living and Working Conditions. http://www.eurofound.europa.eu/pubdocs/2006/98/en/2/ef0698en.pdf

Penney, L. M., ve Spector, P. E. (2005). Job stress, incivility, and counterproductive work behavior (CWB): The moderating role of negative affectivity. Journal of Organizational Behavior, 26(7), 777-796. DOI: 10.1002/job.336

Pritchard, A. (1969). Statistical bibliography or bibliometrics. Journal of Documentation, 25(4), 348-349.

Rugala, E. A., ve Isaacs, A. R. (2003). Workplace violence issues in response.

Savaş, N. Ş., Aslan, F. E., ve Alptekin, H. K. (2020). Acil servislerde yaşanan şiddet olaylarının sağlık profesyonelleri tarafından değerlendirilmesi. Akademik Sosyal Araştırmalar Dergisi, 8(473), 480. DOI: 10.11693/hyhz20181000233

Shaikh, S., Baig, L. A., Hashmi, I., Khan, M., Jamali, S., Khan, M. N., Saleemi, M. A., Zulfiqar, K., Ehsan, S., Yasir, I., Haq, Z., Mazharullah, L., ve Zaib, S. (2020). The Magnitude and Determinants of Violence against Healthcare Workers in Pakistan. BMJ Global Health, 5(4), 1-13. DOI: 10.1136/bmjgh-2019-002112

Singh, G., Singh, A., Chaturvedi, S., ve Khan, S. (2019). Workplace violence against resident doctors: A multicentric study from government medical colleges of uttar pradesh. Indian J Public Health, 63(2), 143-146. DOI: 10.4103/ijph.IJPH_70_18

Speroni, K. G., Fitch, T., Dawson, E., Dugan, L., ve Atherton, M. (2014). Incidence and cost of nurse workplace violence perpetrated by hospital patients or patient isitors. Journal of Emergency Nursing, 40(3), 218-228. DOI: 10.1016/j.jen.2013.05.014

Stadnyk, B. (2004). Posttraumatic stress disorder, violence and quality of life in saskatchewan corrections workers. PhD Thesis, University of Regina, Saskatchewan.

Şimşir, İ. (2021). Bibliyometri ve bibliyometrik analize ilişkin kavramsal çerçeve. O. Öztürk ve G. Gürler (Ed.). Bir Literatür İncelemesi Aracı Olarak Bibliyometrik Analiz. içinde (s. 7-25). Ankara: Nobel Bilimsel Eserler, ISBN: 978-625-7363-30-3 
Tian, Y., Yue, Y., Wang, J., Luo, T., Li, Y., ve Zhou, J. (2020). Workplace violence against hospital healthcare workers in China: A national WeChat-Based Survey. BMC Public Health, 20(1), 1-8. DOI: 10.1186/s12889-020-08708-3

$\mathrm{Wu}, \mathrm{Y}$., Chen, J., Fang, H., and Wan, Y. (2020). Intimate partner violence: A bibliometric review of literature. International Journal of Environmental Research and Public Health, 17(15), 5607. DOI: 10.3390/ijerph17155607

Yıldız, A. N., Kaya, M., and Bilir, N. (2011). Işyerinde şïddet. Türkiye İşçi Sendikaları Konfederasyonu.

\section{Kaynakça Bilgisi / Citation Information}

Seyran, F. (2021). İşyeri şiddeti çalışmalarının bibliyometrik analizi. OPUS-Uluslararası Toplum Araştırmaları Dergisi, 17(36), 2868-2889. DOI: 10.26466/opus. 885707 